\title{
Elective induction for pregnancies at or beyond 41 weeks of gestation and its impact on stillbirths: a systematic review with meta-analysis
}

\author{
Arwa Abbas Hussain, Mohammad Yawar Yakoob, Aamer Imdad, Zulfiqar A Bhutta*
}

\begin{abstract}
Background: An important determinant of pregnancy outcome is the timely onset of labor and birth. Prolonged gestation complicates 5\% to $10 \%$ of all pregnancies and confers increased risk to both the fetus and mother. The purpose of this review was to study the possible impact of induction of labour (IOL) for post-term pregnancies compared to expectant management on stillbirths.
\end{abstract}

Methods: A systematic review of the published studies including randomized controlled trials, quasi- randomized trials and observational studies was conducted. Search engines used were PubMed, the Cochrane Library, the WHO regional databases and hand search of bibliographies. A standardized data abstraction sheet was used. Recommendations have been made for input to the Lives Saved Tool (LiST) model by following standardized guidelines developed by the Child Health Epidemiology Reference Group (CHERG).

Results: A total of 25 studies were included in this review. Meta-analysis of 14 randomized controlled trials (RCTs) suggests that a policy of elective IOL for pregnancies at or beyond 41 weeks is associated with significantly fewer perinatal deaths ( $R R=0.31 ; 95 \% \mathrm{Cl}: 0.11-0.88$ ) compared to expectant management, but no significant difference in the incidence of stillbirth ( $R R=0.29 ; 95 \% \mathrm{Cl}$ : 0.06-1.38) was noted. The included trials evaluating this intervention were small, with few events in the intervention and control group. There was significant decrease in incidence of neonatal morbidity from meconium aspiration $(R R=0.43,95 \% \mathrm{Cl} 0.23-0.79)$ and macrosomia $(R R=0.72 ; 95 \% \mathrm{Cl}$ : $0.54-0.98$ ). Using CHERG rules, we recommended $69 \%$ reduction as a point estimate for the risk of stillbirth with IOL for prolonged gestation (> 41 weeks).

Conclusions: Induction of labour appears to be an effective way of reducing perinatal morbidity and mortality associated with post-term pregnancies. It should be offered to women with post-term pregnancies after discussing the benefits and risks of induction of labor.

\section{Background}

An important determinant of the pregnancy outcome is the timely onset of labor and birth. Both preterm and post-term births are associated with unfavorable maternal and neonatal outcomes. Prolonged gestation complicates $5 \%$ to $10 \%$ of all pregnancies and confers increased risk to both the fetus and mother [1,2]. In the United States, about $18 \%$ of all singleton pregnancies persist beyond 41 weeks, $10 \%$ (range, $3 \%$ to $14 \%$ ) continue beyond 42 weeks and $4 \%$ (range, $2 \%$ to $7 \%$ ) continue

\footnotetext{
* Correspondence: zulfiqar.bhutta@aku.edu

Division of Women and Child Health, The Aga Khan University, Stadium Road, P.O. Box 3500, Karachi, Pakistan
}

(c) 2011 Hussain et al; licensee BioMed Central Ltd. This is an open access article distributed under the terms of the Creative Commons Attribution License (http://creativecommons.org/licenses/by/2.0), which permits unrestricted use, distribution, and reproduction in any medium, provided the original work is properly cited. tric intervention $[2,3]$. Post-term pregnancy is associated with higher rates of stillbirth, macrosomia (birth weight $>4000 \mathrm{gm}$ ), birth injury and meconium aspiration syndrome [2]. The major cause of perinatal morbidity and mortality in post-term pregnancy is presumed to be the progressive uteroplacental insufficiency $[4,5]$.

Many studies have assessed the gestation-specific stillbirth rate which is expressed as the number of stillbirths per 1000 total births at each week of gestation. Divon and colleagues [6] conducted a retrospective analysis of all deliveries in Sweden from 1987 to 1992. They found a statistically significant increase in the odds ratio for fetal death from 41 weeks and beyond. Using fetal mortality at 
40 weeks' gestation as a reference level, the odds ratios for fetal death were $1.5,1.8$, and 2.9 at 41, 42, and 43 weeks, respectively. Perinatal mortality (defined as stillbirths plus early neonatal deaths) at 42 weeks of gestation was twice that at 40 weeks ( 4 to 7 vs. 2 to 3 per 1000 deliveries, respectively) and increases 4 -fold at 43 weeks and 5 - to 7 -fold at 44 weeks [3,7-9].

Currently there are no tests available to ascertain whether it would be better to continue with the pregnancy or to induce birth, or tests that can determine the best possible time for induction [10]. The Society of Obstetricians and Gynecologists of Canada Clinical Practice Guidelines proposed induction of labour between 41 and 42 weeks of gestation [11]. Previously some authors believed that the policy of IOL between 41-42 weeks was a crude approach for reducing stillbirth rates because even though the risk of fetal death is increased post-term, many more fetal deaths occur between 37 and 42 weeks than do so beyond 42 weeks $[12,13]$. However available evidence from clinical trials and systematic reviews do suggest an impact of induction of labour on perinatal mortality. [14].

The purpose of this review was to assess the impact of elective induction of labour for post-term pregnancies (> 41 weeks) of gestation on stillbirths compared to expectant management (policy of awaiting spontaneous onset of labour). This paper is part of a series of papers which seek to estimate effect of an intervention for input into the Lives Saved Tool (LiST) model [15]. An intervention is currently included in the Lives Saved Tool (LiST) model if there is evidence that it reduces maternal mortality, infant/child mortality ( $<5$ years) and/or stillbirths. The process of generating recommendations for an intervention involve qualitative evaluation of available evidence according to adapted GRADE criteria [16] and quantitative evaluation according to Child Health Epidemiology Reference Group (CHERG) rules [15]. For more details of the review methods, the adapted GRADE approach, see the methods section and the CHERG method paper [15].

\section{Methods}

\section{Literature search}

A literature search was conducted using search engines like PubMed, the Cochrane Library and the WHO regional databases. We identified all studies that compared the impact of elective induction of labour versus expectant management, for pregnancies at or beyond 41weeks of gestation, on stillbirths and perinatal mortality (figure 1). Furthermore, hand search of bibliographies of relevant reviews was performed. Experts in the field were contacted for further data or for unpublished trials. We also looked at previous reviews for studies that reported outcomes on morbidities associated with prolonged pregnancy. Morbidities considered in our review include meconium aspiration syndrome, birth asphyxia, and macrosomia. The following search strategy was used:

("Pregnancy, Prolonged"[Mesh] OR "Labor, Induced"[Mesh] OR induction) AND ("Labor, Obstetric"[Mesh] OR labor) AND ("Stillbirth"[Mesh] OR "Perinatal Mortality"[Mesh] OR "Fetal Death"[Mesh] OR Stillbirth* OR "Intrauterine death" OR "perinatal mortality").

For the initial selection, there was no restriction with respect to the language of the article. However, nonEnglish articles were not translated and if the desired information was available in the abstracts then those were used. If full texts could not be retrieved relevant available information was used from the abstract.

\section{Inclusion criteria}

-All studies that were included in our review looked at the impact of elective induction of labour for pregnancies at or beyond 41 weeks on stillbirths or perinatal mortality.

- The study designs selected were randomized controlled trials, quasi experimental studies and observational studies.

- The eligible studies were those that compared the impact of labour induction with expectant management.

- Only those studies were included that evaluated low risk pregnancies i.e. uncomplicated, singleton, and live pregnancies at or beyond 41 completed weeks of gestation.

- Selected studies clearly documented the outcome data on stillbirth and/or perinatal mortality.

- The selected studies could differ in terms of the methods of induction used and/or the techniques used for monitoring of pregnancies that were managed expectantly.

- Only data from RCTs were included in the metaanalyses.

\section{Exclusion criteria}

-

Studies investigating the impact of induction of labour prior to 41 completed weeks on stillbirth and/or perinatal mortality were excluded.

-

Studies that looked at induction of labour for reasons other than prolonged gestation such as macrosomia etc. were excluded.

Studies that included complicated or high-risk pregnancies were excluded.

Studies comparing different methods of labour induction (means no control group with expectant management) or 


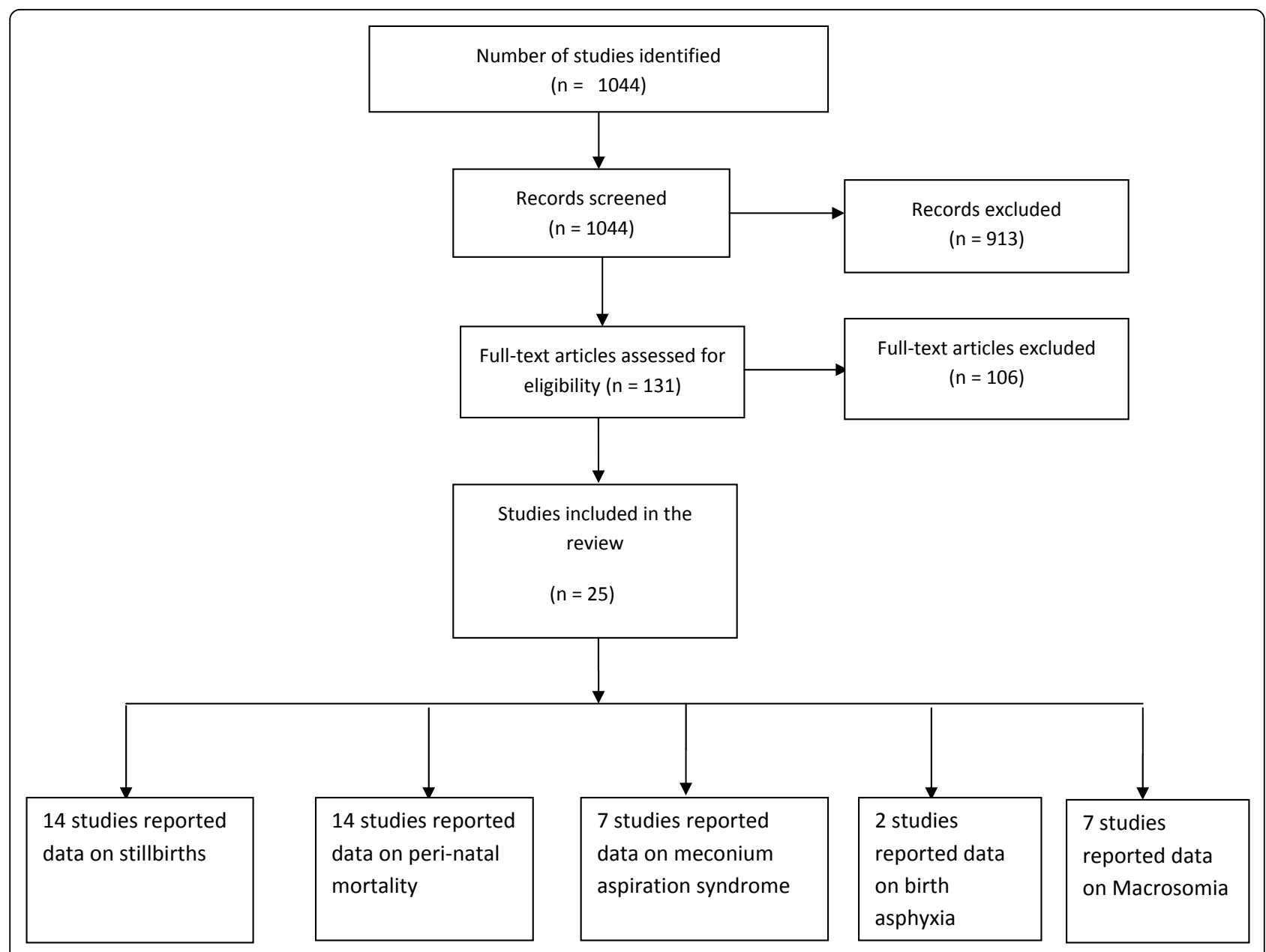

Figure 1 Flow diagram showing identification of studies evaluating induction of labor at or beyond 41 weeks.

those comparing induction at 41 weeks with induction at 42 weeks were excluded.

\section{Validity assessment}

We graded the 'overall' quality of evidence of an outcome according to the CHERG adaptation of the GRADE technique [16]. This technique is based on the following components 1 ) the volume and consistency of the evidence; 2) precision of the effect size or risk ratio; and 3) the level of statistical evidence for an association between the intervention and outcome, as reflected by the $\mathrm{p}$-value $[15,16]$. The individual studies were also graded into 'high', 'moderate', 'low' and 'very low'. Studies were graded 'high' if it were a randomized or cluster randomized trial. The grade was then decreased by one for each study design limitation. The grade was increased by 1-2 for studies reporting a statistically significant level of impact ( $>80 \%$ reduction) or an intentto-treat analysis. A study with a final grade of very low was excluded based on inadequate quality. For more details of the review methods, the adapted GRADE approach or the LiST model see other articles in this supplement.

\section{Data abstraction}

Two researchers' extracted data into a standard web excel sheet designed by the CHERG/LiST review group [15]. The variables included were, for example, location and setting of the study, its design and limitations, allocation concealment, blinding assessment, rates of lost to follow-up, intention-to-treat analysis, definitions of intervention and control group.

\section{Quantitative data synthesis}

The study design considered for meta-analyses included randomized controlled trials only. Meta-analyses were generated using Generic Inverse Variance method of meta-analysis [17]. Quasi-randomized trials and observational studies were also considered for this review, but not included in meta-analyses. The definitions of stillbirth and perinatal mortality were taken as defined by 
the author(s). Summary estimates were described as risk ratios along with 95\% confidence intervals. Fixed models were used for primarily analyses. Statistical heterogeneity among trials was assessed by observing the overlap of the confidence intervals among the studies, Chi square value (P-value) of heterogeneity $\mathrm{I}^{2}$ statistics. A p value $>0.1$ or $\mathrm{I}^{2}$ value $>50 \%$ was taken to represent substantial heterogeneity and random models were used [18].

\section{Results}

\section{Trial flow}

The search strategy identified a total of 1044 records (Fig 1). After initial screening of the titles and abstracts, we selected 131 papers for data on the outcome measures of interest. A total of 25 relevant papers have been included in the final database. The pertinent characteristics of all included studies are given in Additional files 1, 2 and 3. The detailed data extraction with the limitation of studies is shown in Additional File 4.

\section{Results of the meta-analyses}

There were 16 RCTs [19-34] and 3 quasi-experimental studies [35-37] reporting outcome measures of interest. Our meta-analyses of RCTs demonstrated that elective IOL for post-term pregnancies at or beyond 41 weeks, has a statistically significant impact on reducing perinatal mortality ( $R R=0.3195 \%$ CI $0.11-0.88)$, but the impact on stillbirth failed to reach a level of statistical significance $(\mathrm{RR}=0.29 ; 95 \% \mathrm{CI}$ : 0.06-1.38) (figures 2 and 3 respectively). We also calculated number needed to treat (NNT) for perinatal mortality (328 to reduce one case) and stillbirths (657 to avoid one stillbirth). A subgroup analysis for IOL at 41 completed weeks (based on 12 RCTs) showed a statistically significant impact on perinatal mortality ( $R R=0.2795 \%$ CI 0.08-0.98), while the impact on stillbirth remained statistically insignificant ( $R R=0.29$ 95\%CI 0.06-1.38) (data not shown). The results of IOL at 42 weeks based on 2 RCTs showed a statistically insignificant impact on perinatal mortality ( $R R=0.4195 \%$ CI 0.06-2.73), while the impact on stillbirth was not estimable since both the studies reported zero estimates for stillbirth.

Data on morbidities associated with post-term pregnancy were presented in 10 trials [20-25,28,30,32,33] that met our eligibility criteria. We conducted metaanalyses to assess the impact of IOL at or beyond 41 weeks on meconium aspiration syndrome, birth asphyxia, and macrosomia. Our analyses demonstrated a statistically significant reduction in the incidence of meconium aspiration syndrome $(\mathrm{R} R=0.4395 \% \mathrm{CI} 0.23$ 0.79 ) (figure 4) based on seven studies and macrosomia ( $R R=0.72$ 95\% CI 0.54-0.98) (figure 5) also based on seven trials. The impact on birth asphyxia $(R R=1.8695 \%$
CI 0.51-6.76; 2 trials) (figure 6) failed to reach a level of statistical significance.

\section{Evidence from quasi-experimental studies}

Three quasi randomized trials have been included in our study [35-37]. One study comprising of 363 women was conducted in United Kingdom over a period of 21 months. The women were allocated for either IOL $(n=195)$ at 290 days of gestation or expectant management $(n=207)$. The study reported one neonatal death in the induced arm and one stillbirth in the expectant arm [35]. Another prospective study was under taken from September 2000 to September 2001 in Sobhraj maternity hospital in Karachi, Pakistan [36]. This included a total of 100 prolonged uncomplicated pregnancies. Labour was induced in 50 patients at 294 days of gestation while the remaining 50 were managed expectantly. Different methods of induction were used. The choice of method depended on whether or not the cervix was favorable. The study reported a total of 9 perinatal deaths. Perinatal mortality was twice more in the controlled group (5 stillbirths and 1 neonatal death) as compared to the intervention group (2 stillbirths and 1 neonatal death). The difference in perinatal mortality between the two groups was reported as being significant $(\mathrm{P} \leq 0.05)$ [36]. A third study comprising of 156 uncomplicated post-date pregnancies was conducted. The study group comprised of 78 patients who were managed expectantly and the control group consisted of 78 women who were induced labour on day 294 of gestation. This study reported one neonatal death due to severe congenital heart disease in the expectant group and one neonatal death due to asphyxia in the induced group [37].

\section{Evidence from observational studies}

Six relevant observational studies were identified [38-43]. Two of these were prospective studies. One prospective study of 395 singletons, uncomplicated post-term pregnancies was conducted at Queen Alia Military Hospital, Jordan from January 2001 to July 2002 [38]. The study comprised of two groups, one group being managed by IOL $(n=175)$ while the other was managed expectantly $(n=220)$. Labour was induced by inserting dinoprostone $3 \mathrm{mg}$ vaginal pessaries in the posterior vaginal fornix. Continuous fetal heart rate monitoring was done in both groups. The study reported no statistically significant differences in the fetal/ neonatal outcome measures between the two groups. There were no perinatal deaths in either groups $(\mathrm{P}=0.69)$ [38]. Another study addressed the effect of induced labor using pitocin IV drip in decreasing the incidence of perinatal complications and perinatal mortality of prolonged pregnancy [39]. Induced labor was used in a study group comprising of 126 


\begin{tabular}{|c|c|c|c|c|c|c|c|c|}
\hline Study or Subgroup & Induction & $\begin{array}{l}\text { Ion } \\
\text { Total } \\
\end{array}$ & \multicolumn{2}{|c|}{ Expectant } & Weight & \multirow[t]{2}{*}{$\begin{array}{c}\text { Risk Ratio } \\
\text { M-H, Fixed, } 95 \% \mathrm{Cl} \\
\end{array}$} & \multicolumn{2}{|c|}{$\begin{array}{c}\text { Risk Ratio } \\
\text { M-H, Fixed, 95\% Cl }\end{array}$} \\
\hline \multicolumn{8}{|c|}{1.2 .241 completed weeks } & \\
\hline Augensen 1987 & 0 & 214 & 0 & 195 & & Not estimable & & \\
\hline Chanrachkul 2003 & 0 & 124 & 0 & 125 & & Not estimable & & \\
\hline Dyson 1987 & 0 & 152 & 1 & 150 & $10.4 \%$ & $0.33[0.01,8.01]$ & & \\
\hline Gelisen 2005 & 0 & 300 & 1 & 300 & $10.3 \%$ & $0.33[0.01,8.15]$ & & \\
\hline Hannah 1992 & 0 & 1701 & 2 & 1706 & $17.2 \%$ & $0.20[0.01,4.18]$ & & \\
\hline Heimstad 2007 & 0 & 254 & 1 & 254 & $10.3 \%$ & $0.33[0.01,8.14]$ & & \\
\hline Henry 1969 & 0 & 55 & 2 & 57 & $16.9 \%$ & $0.21[0.01,4.22]$ & & \\
\hline James 2001 & 0 & 37 & 0 & 37 & & Not estimable & & \\
\hline Martin 1989 & 0 & 12 & 0 & 10 & & Not estimable & & \\
\hline NICHHD 1994 & 0 & 174 & 0 & 175 & & Not estimable & & \\
\hline Sahraoui 2005 & 0 & 75 & 1 & 75 & $10.3 \%$ & $0.33[0.01,8.05]$ & & \\
\hline Suikkari 1983 & 0 & 66 & 0 & 53 & & Not estimable & & \\
\hline Subtotal $(95 \% \mathrm{Cl})$ & & 3164 & & 3137 & $75.4 \%$ & $0.27[0.08,0.98]$ & & \\
\hline Total events & 0 & & 8 & & & & & \\
\hline \multicolumn{9}{|c|}{ Heterogeneity: $\mathrm{Chi}^{2}=0.13, \mathrm{df}=5(\mathrm{P}=1.00) ; \mathrm{I}^{2}=0 \%$} \\
\hline \multicolumn{9}{|c|}{ Test for overall effect: $Z=1.99(P=0.05)$} \\
\hline \multicolumn{9}{|c|}{ 1.2.3 42 completed weeks } \\
\hline Bergsjo 1989 & 1 & 94 & 2 & 94 & $13.8 \%$ & $0.50[0.05,5.42]$ & & \\
\hline Herabutya 1992 & 0 & 57 & 1 & 51 & $10.9 \%$ & $0.30[0.01,7.18]$ & & \\
\hline Subtotal $(95 \% \mathrm{Cl})$ & & 151 & & 145 & $24.6 \%$ & $0.41[0.06,2.73]$ & & \\
\hline Total events & 1 & & 3 & & & & & \\
\hline \multicolumn{9}{|c|}{ Heterogeneity: $\mathrm{Chi}^{2}=0.06, \mathrm{df}=1(P=0.80) ; \mathrm{I}^{2}=0 \%$} \\
\hline \multicolumn{9}{|c|}{ Test for overall effect: $Z=0.92(P=0.36)$} \\
\hline Total $(95 \% \mathrm{Cl})$ & & 3315 & & 3282 & $100.0 \%$ & $0.31[0.11,0.88]$ & & \\
\hline Total events & 1 & & 11 & & & & & \\
\hline \multicolumn{7}{|c|}{ Heterogeneity: $\mathrm{Chi}^{2}=0.31, \mathrm{df}=7(\mathrm{P}=1.00) ; \mathrm{I}^{2}=0 \%$} & $0.01 \quad 0.1$ & 10 \\
\hline \multicolumn{7}{|c|}{ Test for overall effect: $Z=2.19(P=0.03)$} & $\begin{array}{ll}0.01 & 0.1 \\
\text { avours experimental }\end{array}$ & $\begin{array}{l}10 \\
\text { Favours control }\end{array}$ \\
\hline
\end{tabular}

Figure 2 Induction of labour versus expectant management; Outcome: perinatal death.

prolonged, nulliparous and uncomplicated pregnancies. The control group had 128 prolonged, nulliparous and uncomplicated pregnancies that were managed expectantly. The perinatal mortality was 0 in the study group and $3.1 \%$ in the control group. Also, the asphyxia rate was $8.7 \%$ in the study group and $13.3 \%$ in the control. The percentage of caesarean deliveries was the same in both groups. The results of this study suggest that induced labor is safe, effective and practical in the management of prolonged pregnancies [39].
The remaining 4 studies were retrospective studies. One study compared the outcome of expectant management of post-term pregnancy with active management in Masaryk University, Brno [41]. The study comprised of two groups. Group I included 1906 women, who were managed actively by IOL in the $41^{\text {st }}$ week. Group II included 2008 parturients who were managed expectantly till the end of the $42^{\text {nd }}$ week at which labour was induced. The study reported no differences in perinatal mortality and morbidity between the two groups and 


\begin{tabular}{|c|c|c|c|c|c|c|c|c|}
\hline Study or Subgroup & $\begin{array}{l}\text { Induct } \\
\text { Events }\end{array}$ & $\begin{array}{l}\text { ion } \\
\text { Total }\end{array}$ & Expectant & $\begin{array}{l}\text { ant } \\
\text { Total }\end{array}$ & Weight & $\begin{array}{c}\text { Risk Ratio } \\
\text { M-H, Fixed, } 95 \% \mathrm{Cl} \\
\end{array}$ & \multicolumn{2}{|c|}{$\begin{array}{c}\text { Risk Ratio } \\
\text { M-H, Fixed, } 95 \% \mathrm{Cl}\end{array}$} \\
\hline \multicolumn{9}{|c|}{2.2 .241 completed weeks } \\
\hline Augensen 1987 & 0 & 214 & 0 & 195 & & Not estimable & & \\
\hline Chanrachkul 2003 & 0 & 124 & 0 & 125 & & Not estimable & & \\
\hline Dyson 1987 & 0 & 152 & 0 & 150 & & Not estimable & & \\
\hline Gelisen 2005 & 0 & 300 & 1 & 300 & $21.5 \%$ & $0.33[0.01,8.15]$ & & \\
\hline Hannah 1992 & 0 & 1701 & 2 & 1706 & $35.8 \%$ & $0.20[0.01,4.18]$ & $\longleftarrow$ & \\
\hline Heimstad 2007 & 0 & 254 & 0 & 254 & & Not estimable & & \\
\hline Henry 1969 & 0 & 55 & 1 & 57 & $21.1 \%$ & $0.35[0.01,8.30]$ & & \\
\hline James 2001 & 0 & 37 & 0 & 37 & & Not estimable & & \\
\hline Martin 1989 & 0 & 12 & 0 & 10 & & Not estimable & & \\
\hline NICHHD 1994 & 0 & 174 & 0 & 175 & & Not estimable & & \\
\hline Sahraoui 2005 & 0 & 75 & 1 & 75 & $21.5 \%$ & $0.33[0.01,8.05]$ & & \\
\hline Suikkari 1983 & 0 & 66 & 0 & 53 & & Not estimable & & \\
\hline Subtotal $(95 \% \mathrm{Cl})$ & & 3164 & & 3137 & $100.0 \%$ & $0.29[0.06,1.38]$ & & \\
\hline Total events & 0 & & 5 & & & & & \\
\hline \multicolumn{9}{|c|}{ Heterogeneity: $\mathrm{Chi}^{2}=0.08, \mathrm{df}=3(\mathrm{P}=0.99) ; \mathrm{I}^{2}=0 \%$} \\
\hline \multicolumn{9}{|c|}{ Test for overall effect: $Z=1.56(P=0.12)$} \\
\hline \multicolumn{9}{|c|}{ 2.2.3 42 completed weeks } \\
\hline Bergsjo 1989 & 0 & 94 & 0 & 94 & & Not estimable & & \\
\hline Herabutya 1992 & 0 & 57 & 0 & 51 & & Not estimable & & \\
\hline Subtotal $(95 \% \mathrm{Cl})$ & & 151 & & 145 & & Not estimable & & \\
\hline Total events & 0 & & 0 & & & & & \\
\hline \multicolumn{9}{|c|}{ Heterogeneity: Not applicable } \\
\hline \multicolumn{9}{|c|}{ Test for overall effect: Not applicable } \\
\hline Total $(95 \% \mathrm{Cl})$ & & 3315 & & 3282 & $100.0 \%$ & $0.29[0.06,1.38]$ & & \\
\hline Total events & 0 & & 5 & & & & & \\
\hline \multicolumn{7}{|c|}{ Heterogeneity: $\mathrm{Chi}^{2}=0.08, \mathrm{df}=3(P=0.99) ; I^{2}=0 \%$} & $0.01 \quad 0.1$ & $10 \quad 100$ \\
\hline \multicolumn{7}{|c|}{ Test for overall effect: $Z=1.56(P=0.12)$} & $\begin{array}{ll}0.01 & 0.1 \\
\text { avours experimental }\end{array}$ & $\begin{array}{l}10 \\
\text { Favours control }\end{array}$ \\
\hline
\end{tabular}

Figure 3 Induction of labour versus expectant management; Outcome: stillbirth.

concluded that there was no need to consider the expectant management of the post-term pregnancies to be dangerous [41]. Similar conclusion was drawn by a retrospective analysis comparing the outcomes of postterm pregnancies managed actively by labour inductions beginning at 42 weeks with expectant management of labour [40]. The induced group comprised of 185 women while the group with spontaneous onset of labour had 119 women. One stillbirth occurred in both groups. There was also no statistical difference in the maternal or fetal morbidity between the two groups thus suggesting that standard clinical management is sufficient to assure optimal perinatal outcome in postterm pregnancies [40].

A study conducted in Canada assessed changes in the rates of labour induction in post-term pregnancies and its effects on the rates of stillbirth and cesarean section during1980-1995 [42]. This study demonstrated a significant increase in the rates of labour induction among women delivering at 41 or more weeks' gestation in all 


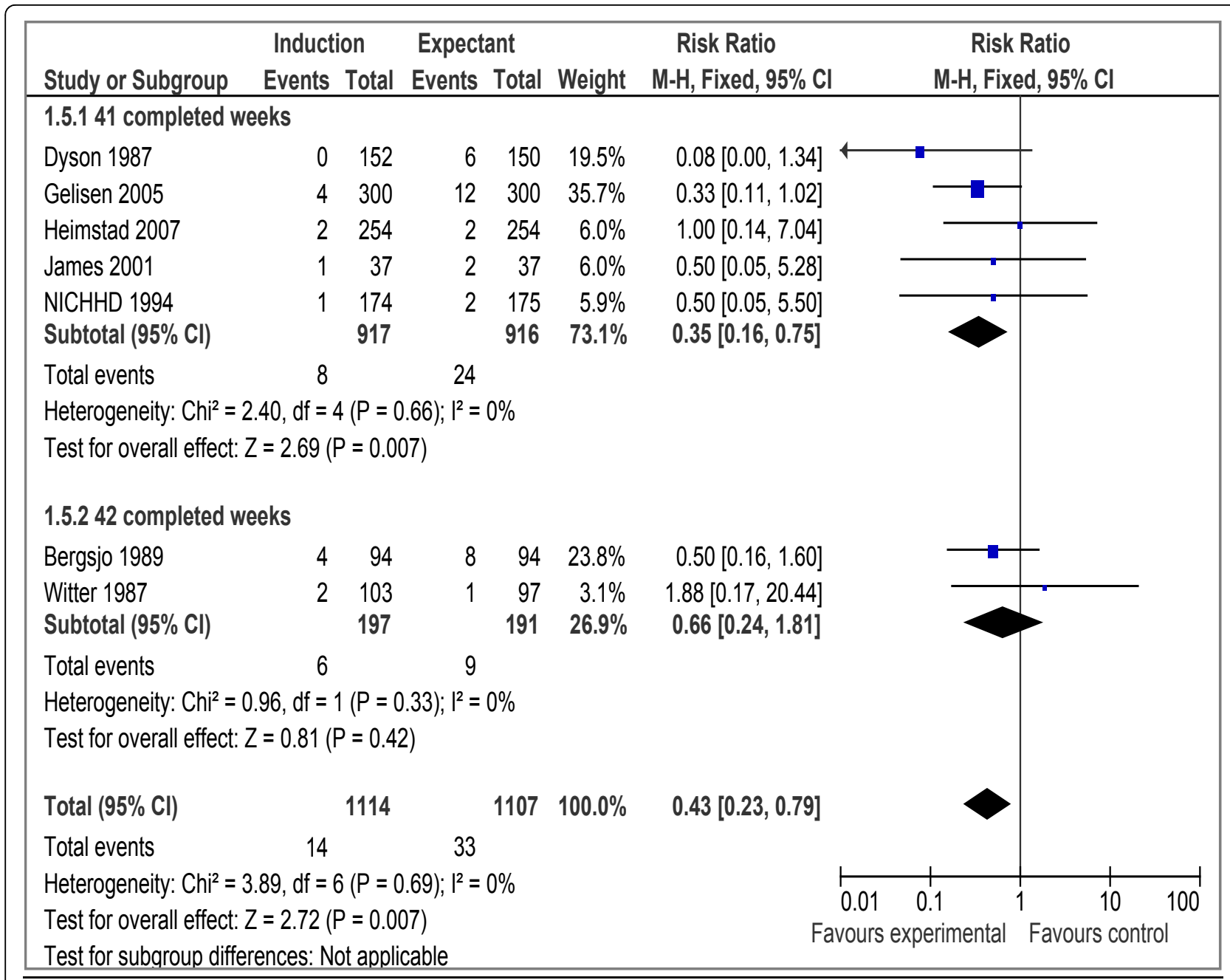

Figure 4 Induction of labour versus expectant management; Outcome: Meconium Aspiration Syndrome.

hospitals and provinces studied. The rate of stillbirth among deliveries at 41 or more weeks' gestation decreased significantly, from 2.8 per 1000 total births in 1980 to 0.9 per 1000 total births in 1995 ( $\mathrm{p}<0.001$ ). The study concluded that the increased rate of labour induction at 41 or more weeks' gestation may have contributed to the decreased stillbirth rates [42]. An observational study compared the impact of IOL with spontaneous onset of labour among post term pregnancies ( $>$ or $=294$ days) between July 1980 -December 1984 at Chicago Lying-In Hospital. The study comprised of 12,930 deliveries from which 707 gestations were prolonged (5.5\%). Labor started spontaneously in $62 \%$, and $38 \%$ underwent induction; the perinatal mortality was 20.5/1000 among those with spontaneous onset of labor while no deaths occurred among those in whom labour was induced. The study concluded that prolonged gestation had a high perinatal morbidity and mortality rate and "active management" (induction at 42 weeks) prevented perinatal deaths in this group thereby justifying an active approach for post-term pregnancies [43].

\section{Discussion}

Meta-analyses of randomized controlled trials demonstrate that a policy of induction of labour for pregnancies at or beyond 41 weeks as compared to expectant management of gestation is associated with fewer perinatal deaths, but no significant difference in the rate of stillbirth. The above mentioned results are in accordance to the findings of the Cochrane review by Gulmezoglu et al 2009 [10]. This review included a total of 12 trials and reported a non-significant reduction in stillbirth risk $(\mathrm{RR}=0.28$, 95\% CI: 0.05-1.67), but a statistically significant reduction in perinatal mortality $(\mathrm{RR}=0.30,95 \% \mathrm{CI}$ : 0.09-0.99). An update of this Cochrane review having 14 trials reports similar results [Stillbirth: 41 complete weeks $(\mathrm{RR}=0.29 ; 95 \% \mathrm{CI}: 0.06-1.38), 42$ complete weeks (not estimable); perinatal death: 41 complete 


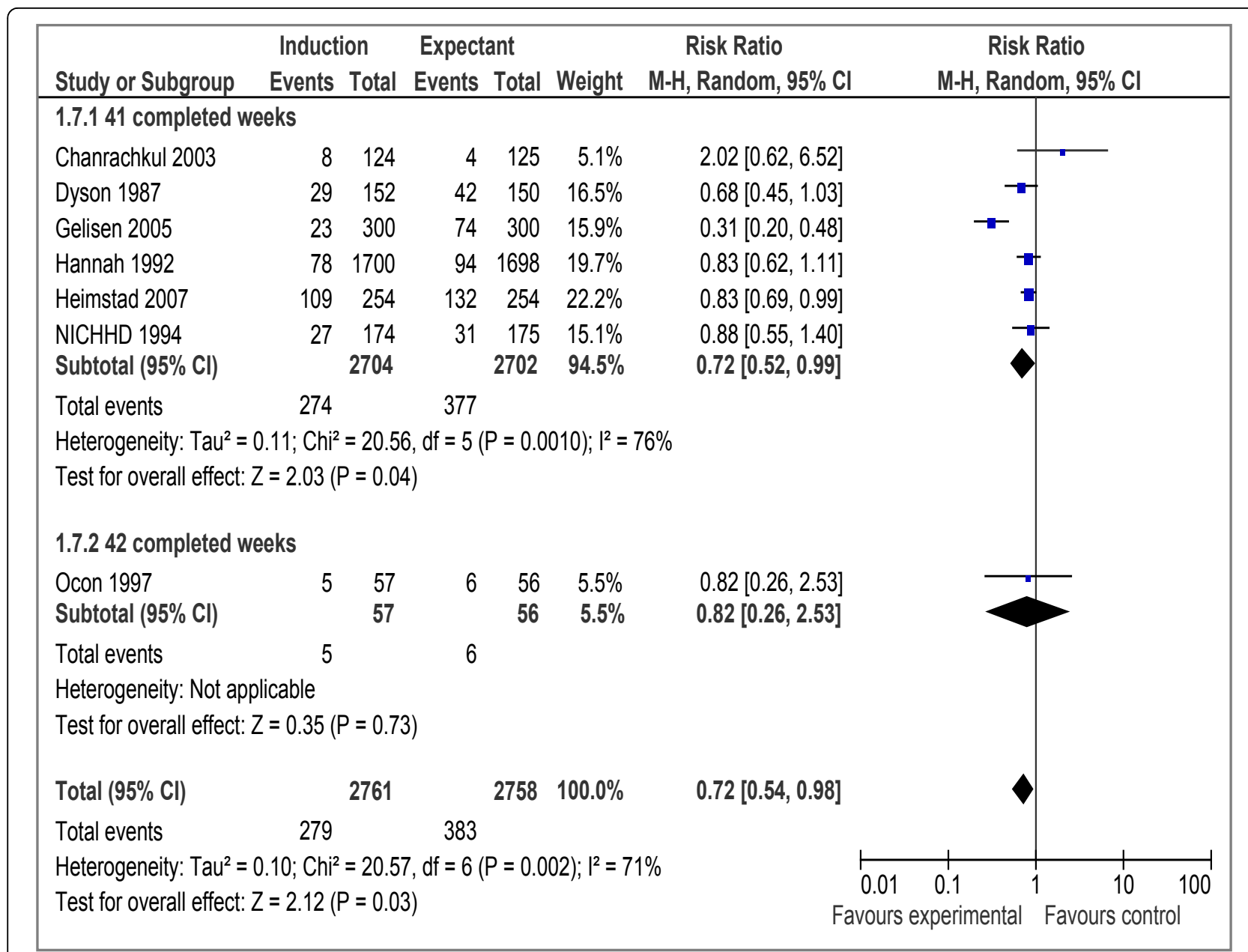

Figure 5 Induction of labour versus expectant management; Outcome: macrosomia (birth weight > 4000gm).

weeks ( $R R=0.27 ; 95 \%$ CI: $0.08-0.98)$, 42 complete weeks ( $R R=0.41 ; 95 \% \mathrm{CI}$ : $0.06-2.73$ ) (Gulmezoglu M and Middleton P 2010, personal communication). The Cochrane review also included trials that compared the impact of IOL with expectant management between 37-40 completed weeks. In our review we have focused only on pregnancies at or beyond 41 weeks. This is based on the fact that most of the complications of prolonged pregnancy are known to increase beyond this gestational age $[1,6,8,44,45]$. Our review also includes data from quasi experimental studies and observational studies and we have used CHERG rules and GRADE criteria for selection of an appropriate estimate for inclusion in the LiST model.

Two systemic reviews by Wennerholm et al. 2009 [46] and Sanchez-Ramos et al. 2003 [5] also analyzed the impact of labour induction on stillbirths and perinatal mortality. Both reviews included a total of 13 trials. These reviews, like ours had included only those studies in their meta-analysis that reported the impacts of labour induction at or beyond 41 weeks of gestation. Neither of these two reviews, however, reported a significant difference in the rate of stillbirth or perinatal mortality between active and expectant management of post-term pregnancy. The review by Sanchez-Ramos also included the studies by Cardozo et al 1986 and Katz et al 1983, while we excluded these studies from our meta-analysis because these were both quasi-experimental studies. These studies have also been excluded from the review by Gulmezoglu et al. 2009 and Wennerholm et al. 2009 on basis of them being alternate allocation trials. We also included one study by Suikkari et al. [31] that was published as an abstract only. This study was not present in Wennerholm review but included in both Gulmezoglu and Sanchez-Ramos review. A study by Sahraoui et al. published in 2005, has been included in our review, while none of the other three reviews have included it [34]. Another recent trial by Heimstad et al. [25] published in 2007 has been included in our review and the review by Wennerholm et al 2009, but is not present in either 


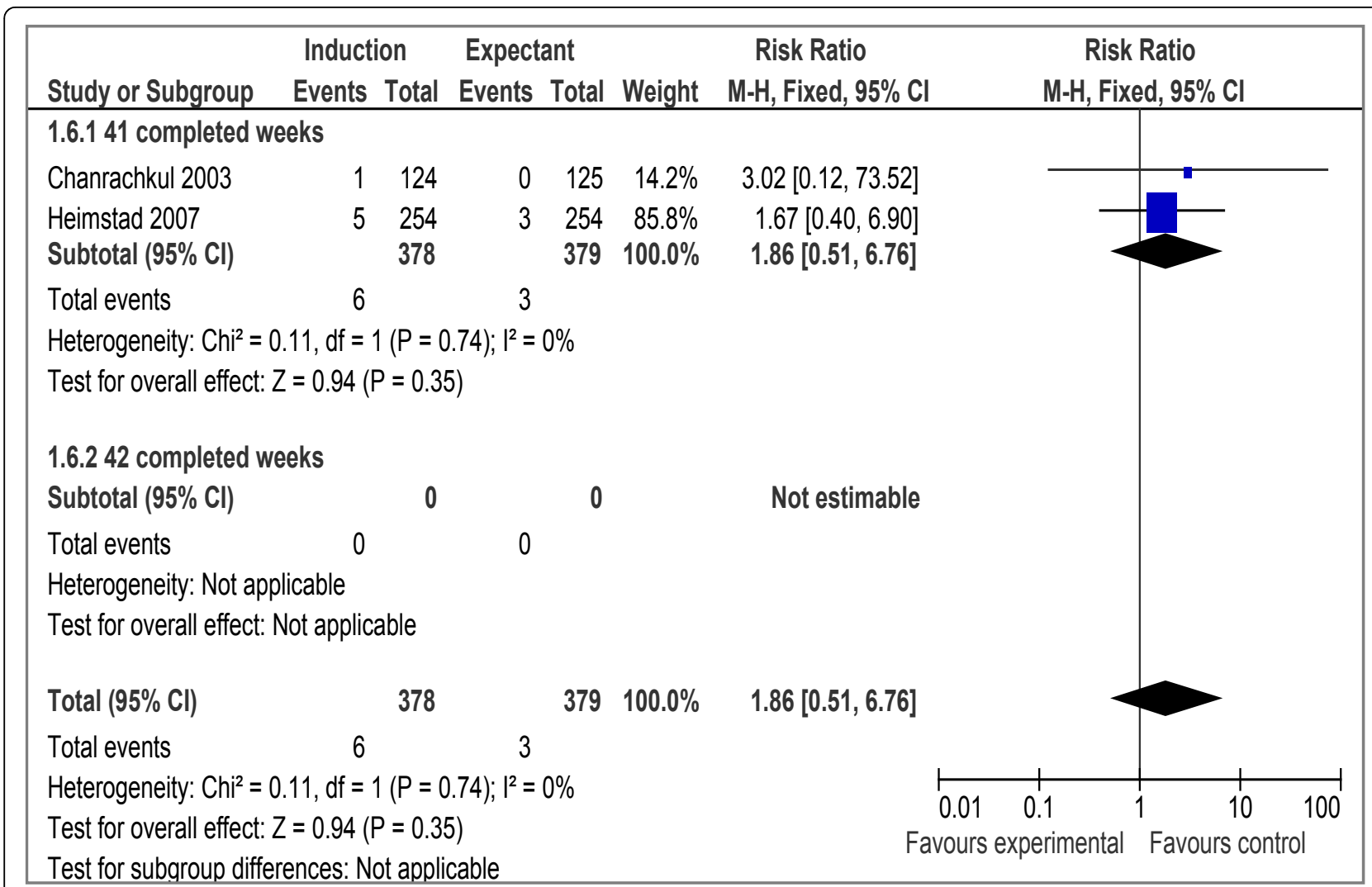

Figure 6 Induction of labour versus expectant management Outcome: Outcome: Birth Asphyxia.

Gulmezoglu or Sanchez-Ramos review. We have excluded any non-english article that was not translated and for which the abstract did not provide adequate data. The same approach was used by Wennerholm et al. The reviews by Sanchez Ramos et al. or Gulmezoglu et al. did not exclude studies based on this criterion. However, there were no additional studies in either of the latter reviews that were not included in our review. Hence, it is unlikely that we have missed out any clinical trial because it was published in a language other than English.

\section{Recommendations for LiST}

Table 1 shows the qualitative assessment of overall evidence regarding induction of labor at 41 weeks and beyond. The pooled estimate from 14 randomized controlled trials showed a non-significant reduction in stillbirths $[R R=0.29,95 \%$ CI 0.06-1.38] and a significant reduction in perinatal mortality $[R R=0.31,95 \% \mathrm{CI}$ $0.11-0.88$. We graded the overall quality of evidence for stillbirths and perinatal mortality as 'moderate'. This assessment was based on the fact that most of the studies were conducted in developed country settings and numbers of events were relatively few in the intervention and control groups. Using CHERG rules, we recommend a reduction in perinatal mortality (i.e. $69 \%$ ) as a surrogate for reduction in stillbirths. The reason for recommending perinatal mortality as surrogate for stillbirths was based on the fact most of the studies do not report disaggregated data for stillbirths but do so for perinatal mortality. In order to further support this assumption we pooled the data for early neonatal mortality in the included studies and the results showed a non-significant $(R R=0.37$; 95\% CI: $0.10-1.38)$ reduction in early neonatal mortality (data not shown). We suggest that the main effect of IOL in the combined outcome of 'perinatal mortality' could be due to stillbirths. Further evidence of effectiveness of IOL at 41 weeks comes from the fact that this approach reduces incidence of morbidities like meconium aspiration syndrome ( $R R=0.4395 \%$ CI 0.23 - 0.79) and macrosomia ( $\mathrm{RR}=0.72$ 95\% CI 0.54-0.98).

As the number of stillbirths in the randomized trials was relatively small, we also included observational studies in our review. Although the quality of evidence derived from observational studies is generally considered poor, it is worth considering data from these studies. The, evidence from observational studies included is variable, half of the studies showed a significant difference in the rate of stillbirth and perinatal death for active versus expectant management, thereby advocating the use of 
Table 1 Quality assessment of trials of elective induction of labour versus expectant management for post-term pregnancies

\begin{tabular}{|c|c|c|c|c|c|c|c|c|}
\hline \multirow[b]{3}{*}{$\begin{array}{l}\text { No of } \\
\text { studies } \\
\text { (ref) }\end{array}$} & \multirow[b]{3}{*}{ Design } & \multicolumn{2}{|r|}{ Quality Assessment } & & & \multicolumn{3}{|c|}{ Summary of Findings } \\
\hline & & & & \multicolumn{2}{|c|}{ Directness } & \multicolumn{2}{|c|}{ No of events } & \multirow[b]{2}{*}{$\begin{array}{l}\text { Relative Risk } \\
(95 \% \mathrm{Cl})\end{array}$} \\
\hline & & Limitations & Consistency & $\begin{array}{l}\text { Generalizability } \\
\text { to population } \\
\text { of interest }\end{array}$ & $\begin{array}{l}\text { Generalizability } \\
\text { to intervention } \\
\text { of interest }\end{array}$ & Intervention & Control & \\
\hline \multicolumn{9}{|c|}{ Mortality (Stillbirth): 'MODERATE' outcome specific quality } \\
\hline 14 & $\begin{array}{l}\text { All RCTs; only } 4 \text { out of } 14 \text { RCTs } \\
\text { report estimable differences in } \\
\text { stillbirth between the two } \\
\text { groups }\end{array}$ & $\begin{array}{l}\text { Small sample size in } 12 \\
\text { studies; result statistically } \\
\text { insignificant; wide Cl: } \\
\text { low precision }\end{array}$ & $\begin{array}{l}\text { All studies are consistent in showing a } \\
\text { tendency towards reduction of stillbirth as } \\
\text { an outcome i.e. the direction of effect is } \\
\text { towards benefit }\end{array}$ & $\begin{array}{l}5 \text { in developing } \\
\text { countries; rest in } \\
\text { developed }\end{array}$ & Yes & 0 & 4 & $\begin{array}{l}\text { RR (fixed): } 0.29 \\
\quad(0.06-1.38)\end{array}$ \\
\hline \multicolumn{9}{|c|}{ Mortality (Perinatal mortality): 'MODERATE' outcome specific quality } \\
\hline 14 & $\begin{array}{l}\text { All RCTs; only } 8 \text { out of } 14 \text { RCTs } \\
\text { report estimable differences in } \\
\text { perinatal mortality between the } \\
\text { two groups }\end{array}$ & $\begin{array}{l}\text { Small sample size in } 12 \\
\text { studies }\end{array}$ & $\begin{array}{l}\text { All studies are consistent in showing a } \\
\text { tendency towards reduction in perinatal } \\
\text { mortality as an outcome i.e. the direction of } \\
\text { effect is towards benefit }\end{array}$ & $\begin{array}{l}5 \text { in developing } \\
\text { countries; rest in } \\
\text { developed }\end{array}$ & Yes & 1 & 10 & $\begin{array}{l}\text { RR (fixed): } 0.31 \\
\quad(0.11-0.88)\end{array}$ \\
\hline \multicolumn{9}{|c|}{ Serious morbidity (Meconium aspiration syndrome):'MODERATE' outcome specific quality } \\
\hline 7 & All RCTs & $\begin{array}{l}\text { Small sample sizes in all } \\
\text { studies }\end{array}$ & $\begin{array}{l}\text { Consistent with } 5 / 7 \text { studies showing } \\
\text { direction of benefit }\end{array}$ & $\begin{array}{l}3 \text { out of } 7 \text { in } \\
\text { developing } \\
\text { countries }\end{array}$ & Yes & 14 & 33 & $\begin{array}{l}\text { RR (fixed): } 0.43 \\
(0.23-0.79)\end{array}$ \\
\hline \multicolumn{9}{|c|}{ Serious morbidity (Birth asphyxia): 'MODERATE' outcome specific quality } \\
\hline 2 & RCTs & Small sample sizes & $\begin{array}{l}\text { Both the studies show a direction towards } \\
\text { increased risk }\end{array}$ & $\begin{array}{l}1 / 2 \text { in } \\
\text { developing } \\
\text { countries }\end{array}$ & Yes & 6 & 3 & $\begin{array}{l}\text { RR (fixed): } 1.86 \\
\quad(0.51-6.76)\end{array}$ \\
\hline \multicolumn{9}{|c|}{ Mild morbidity (Macrosomia): 'MODERATE' outcome specific quality } \\
\hline 7 & All RCTs & $\begin{array}{l}\text { Small sample sizes } \\
\text { except in one study }\end{array}$ & $\begin{array}{l}\text { 6/7 studies showing direction of benefit i.e. } \\
\text { consistent }\end{array}$ & $\begin{array}{l}\text { 2/7 in } \\
\text { developing } \\
\text { countries }\end{array}$ & Yes & 279 & 383 & $\begin{array}{l}\text { RR (random): } 0.72 \\
\quad(0.54-0.98)\end{array}$ \\
\hline
\end{tabular}


routine IOL for post-term pregnancies. A large scale study conducted in Canada by Sue-A-Quan et al. [42] showed a significant reduction in the rate of stillbirths as the rates of elective IOL at or beyond 41 weeks of gestation increased $(\mathrm{p}<0.001)$ in the years 1980 to 1995. Another study [43] comprising of a fairly large number of cases of prolonged gestation showed that the rate of perinatal mortality was significantly higher in patients in whom spontaneous labour was awaited while no deaths were reported in the induced women. The only large scale study showing no difference in perinatal mortality between the two groups was a study by Maly et al. [41]. The remaining studies had very small sample sizes, which do not have sufficient power to detect differences in perinatal mortality and/or stillbirths.

\section{Conclusions}

There is a well-established increased risk of adverse perinatal outcome with pregnancies that extend into the postterm period. Routine induction of labour (at or beyond 41 weeks) seems to be the likely solution for preventing perinatal morbidity and mortality associated with post term pregnancy. Data on stillbirths show no significant effect of IOL post term. Using CHERG rules we propose to use a reduction of $69 \%$ (derived from effect on perinatal mortality) in incidence of stillbirths for inclusion in the LiST model for the effect of induction of labour post term.

\section{Key Messages}

- Elective IOL for prolonged pregnancies at or beyond 41 leads to significant reduction in perinatal mortality [RR $0.3195 \%$ CI 0.11-0.88] but a non-significant reduction in stillbirths [0.29, 95 \% CI 0.06-1.38].

- There was a significant reduction of $57 \%$ in the incidence of meconium aspiration syndrome (MAS) and a non-significant impact for birth asphyxia with the use of elective IOL post term.

- There was a significant $28 \%$ reduction in the incidence of macrosomia ( $R R=0.7295 \%$ CI 0.54-0.98) with elective IOL.

- Given the association of IOL beyond 41 weeks with reduction in perinatal deaths and assuming these are mostly due to stillbirths, we are recommending an effect size of $69 \%$ reduction of risk of stillbirth with IOL for pregnancies beyond 41 weeks gestation.

\section{Additional material}

Additional file 1: Characteristics of included Studies; Randomized Controlled Trials

Additional file 2: Characteristics of included studies: Quasiexperimental trials

Additional file 3: Characteristics of included studies: Observational studies.
Additional file 4: Data extraction sheet for studies included in the review.

\section{Acknowledgements}

This work was supported in part by a grant to the US Fund for UNICEF from the Bill \& Melinda Gates Foundation (grant 43386) to "Promote evidencebased decision making in designing maternal, neonatal and child health interventions in low- and middle-income countries".

This article has been published as part of BMC Public Health Volume 11 Supplement 3, 2011: Technical inputs, enhancements and applications of the Lives Saved Tool (LiST). The full contents of the supplement are available online at http://www.biomedcentral.com/1471-2458/11?issue=S3.

\section{Authors' Contributions}

Professor Zulfiqar A Bhutta developed the review parameters and secured support. Dr. Arwa Abbas Hussain and Dr. Mohammad Yawar Yakoob did the literature search, data extraction and analysis under the supervision of Professor Bhutta. Dr. Aamer Imdad contributed to later revision of the manuscript. Dr. Zulfiqar A. Bhutta gave advice in all the aspects of the project and was the overall supervisor.

\section{Competing interests}

The authors declare no competing interests

Published: 13 April 2011

\section{References}

1. Olesen AW, Westergaard JG, Olsen J: Perinatal and maternal complications related to postterm delivery: a national register-based study, 1978-1993. Am J Obstet Gynecol 2003, 189(1):222-227.

2. Norwitz ER, Snegovskikh W, Caughey AB: Prolonged pregnancy: when should we intervene? Clin Obstet Gynecol 2007, 50(2):547-557.

3. Gynecologists ACoOa: Management of Postterm Pregnancy. ACOG Practice Bulletin No 55 Washington, DC: ACOG; 2004.

4. Rosen MG, Dickinson JC: Management of post-term pregnancy. N Engl J Med 1992, 326(24):1628-1629.

5. Sanchez-Ramos L, Olivier F, Delke I, Kaunitz AM: Labor induction versus expectant management for postterm pregnancies: a systematic review with meta-analysis. Obstet Gynecol 2003, 101(6):1312-1318.

6. Divon MY, Haglund B, Nisell H, Otterblad PO, Westgren M: Fetal and neonatal mortality in the postterm pregnancy: the impact of gestational age and fetal growth restriction. Am J Obstet Gynecol 1998, 178(4):726-731.

7. Rand L, Robinson JN, Economy KE, Norwitz ER: Post-term induction of labor revisited. Obstet Gynecol 2000, $96(5$ Pt 1):779-783.

8. Hilder L, Costeloe K, Thilaganathan B: Prolonged pregnancy: evaluating gestation-specific risks of fetal and infant mortality. Br J Obstet Gynaecol 1998, 105(2):169-173.

9. Cotzias CS, Paterson-Brown S, Fisk NM: Prospective risk of unexplained stillbirth in singleton pregnancies at term: population based analysis. BMJ 1999, 319(7205):287-288.

10. Gulmezoglu AM, Crowther CA, Middleton P: Induction of labour for improving birth outcomes for women at or beyond term. Cochrane Database Syst Rev 2006, , 4: CD004945.

11. Canada MFMCotSoOaGo: Post-term pregnancy (committee opinion). SOGC clinical practice guidelines No 151997.

12. Hollis B: Prolonged pregnancy. Curr Opin Obstet Gynecol 2002, 14(2):203-207.

13. Swift J: Routine induction of labour at 41 weeks gestation: nonsensus consensus. BJOG: an International Journal of Obstetrics and Gynaecology 2002, 109:485-491.

14. Mandruzzato G, Alfirevic Z, Chervenak F, Gruenebaum A, Heimstad R, Heinonen S, Levene M, Romero R, Salvesen K, Saugstad O, et al: Guidelines for the management of postterm pregnancy. J Perinat Med 2010, 38(2):111-119.

15. Walker N, Fischer-Walker C, Bryce J, Bahl R, Cousens S: Standards for CHERG reviews of intervention effects on child survival. Int J Epidemiol 2010, 39(Suppl 1):i21-31. 
16. Atkins D, Best D, Briss PA, Eccles M, Falck-Ytter $Y$, Flottorp S, Guyatt GH, Harbour RT, Haugh MC, Henry D, et al: Grading quality of evidence and strength of recommendations. BMJ 2004, 328(7454):1490.

17. RevMan: The Cochrane Colloboration. Review Manager (RevMan) 5 for Windows. Oxford England 2003.

18. Cochrane Handbook for Systematic Reviews of Interventions Version 5.0.2 2008. Higgins J, Green S 2009 [http://www.cochrane-handbook.org]

19. Augensen K, Bergsjo P, Eikeland T, Askvik K, Carlsen J: Randomised comparison of early versus late induction of labour in post-term pregnancy. Br Med J (Clin Res Ed) 1987, 294(6581):1192-1195.

20. Bergsjo P, Huang GD, Yu SQ, Gao ZZ, Bakketeig LS: Comparison of induced versus non-induced labor in post-term pregnancy. A randomized prospective study. Acta Obstet Gynecol Scand 1989, 68(8):683-687.

21. Chanrachakul $B$, Herabutya $Y$ : Postterm with favorable cervix: is induction necessary? Eur J Obstet Gynecol Reprod Biol 2003, 106(2):154-157.

22. Dyson DC, Miller PD, Armstrong MA: Management of prolonged pregnancy: induction of labor versus antepartum fetal testing. Am J Obstet Gynecol 1987, 156(4):928-934

23. Gelisen O, Caliskan E, Dilbaz S, Ozdas E, Dilbaz B, Haberal A: Induction of labor with three different techniques at 41 weeks of gestation or spontaneous follow-up until 42 weeks in women with definitely unfavorable cervical scores. Eur J Obstet Gynecol Reprod Biol 2005, 120(2):164-169.

24. Hannah ME, Hannah WJ, Hellmann J, Hewson S, Milner R, Willan A: Induction of labor as compared with serial antenatal monitoring in postterm pregnancy. A randomized controlled trial. The Canadian Multicenter Post-term Pregnancy Trial Group. N Engl J Med 1992, 326(24):1587-1592

25. Heimstad R, Skogvoll E, Mattsson LA, Johansen OJ, Eik-Nes SH, Salvesen KA: Induction of labor or serial antenatal fetal monitoring in postterm pregnancy: a randomized controlled trial. Obstet Gynecol 2007, 109(3):609-617.

26. Henry GR: A controlled trial of surgical induction of labour and amnioscopy in the management of prolonged pregnancy. J Obstet Gynaecol Br Commonw 1969, 76(9):795-798.

27. Herabutya $Y$, Prasertsawat $P O$, Tongyai T, Isarangura Na Ayudthya N: Prolonged pregnancy: the management dilemma. Int J Gynaecol Obstet 1992, 37(4):253-258.

28. James C, George SS, Gaunekar N, Seshadri L: Management of prolonged pregnancy: a randomized trial of induction of labour and antepartum foetal monitoring. Natl Med J India 2001, 14(5):270-273.

29. Martin JN Jr., Sessums JK, Howard P, Martin RW, Morrison JC: Alternative approaches to the management of gravidas with prolonged-posttermpostdate pregnancies. J Miss State Med Assoc 1989, 30(4):105-111.

30. A clinical trial of induction of labor versus expectant management in postterm pregnancy. The National Institute of Child Health and Human Development Network of Maternal-Fetal Medicine Units. Am J Obstet Gynecol 1994, 170(3):716-723.

31. Suikkari AM, Jalkanen M, Heiskala H, Koskela O: Prolonged pregnancy: induction or observation. Acta Obstetricia et Gynecologica Scandinavica Supplement 1983, 116:58

32. Ocon L, Hurtado R, Coteron JJ, Zubiria A, Ramirez O, Garcia JA: Prolonged pregnancy: procedure guidelines [Gestacion prolongada: pautas de actuacion]. Progresos de Obstetricia y Ginecologia 1997, 40:101-106.

33. Witter FR, Weitz CM: A randomized trial of induction at 42 weeks gestation versus expectant management for postdates pregnancies. Am J Perinatol 1987, 4(3):206-211.

34. Sahraoui W, Hajji S, Bibi M, Nouira M, Essaidi H, Khairi H: Management of pregnancies beyond forty-one week's gestation with an unfavorable cervix. J Gynecol Obstet Biol Reprod (Paris) 2005, 34(5):454-462.

35. Cardozo L, Fysh J, Pearce JM: Prolonged pregnancy: the management debate. Br Med J (Clin Res Ed) 1986, 293(6554):1059-1063.

36. Iqbal S: Management of prolonged pregnancy. J Coll Physicians Surg Pak 2004, 14(5):274-277.

37. Katz Z, Yemini M, Lancet M, Mogilner BM, Ben-Hur H, Caspi B: Nonaggressive management of post-date pregnancies. Eur J Obstet Gynecol Reprod Biol 1983, 15(2):71-79.

38. Al-Taani M: Pregnancies past the estimated date of confinement: labour and delivery outcome. East Mediterr Health J 2003, 9(5-6):955-960.

39. Bian $X$ : Exploration of the clinical management of prolonged pregnancy. Zhongguo Yi Xue Ke Xue Yuan Xue Bao 1990, 12(2):137-141.
40. Hauth JC, Goodman MT, Gilstrap LC 3rd, Gilstrap JE: Post-term pregnancy. I. Obstet Gynecol 1980, 56(4):467-470.

41. Maly Z, Grosmanova A, Pulkrabkova S, Gogela J: Effect of birth weight on neonatal and maternal morbidity in expectant management of postterm pregnancy. Ceska Gynekol 2002, 67(Suppl 1):20-22.

42. Sue AQAK, Hannah ME, Cohen MM, Foster GA, Liston RM: Effect of labour induction on rates of stillbirth and cesarean section in post-term pregnancies. CMAJ 1999, 160(8):1145-1149.

43. Votta RA, Cibils LA: Active management of prolonged pregnancy. Am J Obstet Gynecol 1993, 168(2):557-563.

44. Zeitlin J, Blondel B, Alexander S, Breart G: Variation in rates of postterm birth in Europe: reality or artefact? BJOG 2007, 114(9):1097-1103.

45. Campbell MK, Ostbye T, Irgens LM: Post-term birth: risk factors and outcomes in a 10-year cohort of Norwegian births. Obstet Gynecol 1997, 89(4):543-548.

46. Wennerholm UB, Hagberg H, Brorsson B, Bergh C: Induction of labor versus expectant management for post-date pregnancy: is there sufficient evidence for a change in clinical practice? Acta Obstet Gynecol Scand 2009, 88(1):6-17.

doi:10.1186/1471-2458-11-S3-S5

Cite this article as: Hussain et al: Elective induction for pregnancies at or beyond 41 weeks of gestation and its impact on stillbirths: a systematic review with meta-analysis. BMC Public Health 2011 11(Suppl 3):S5.

\section{Submit your next manuscript to BioMed Central and take full advantage of:}

- Convenient online submission

- Thorough peer review

- No space constraints or color figure charges

- Immediate publication on acceptance

- Inclusion in PubMed, CAS, Scopus and Google Scholar

- Research which is freely available for redistribution 